OPEN ACCESS

Edited by:

Rino Bellocco,

University of Milano-Bicocca, Italy

Reviewed by:

Essi Hantikainen,

Eurac Research, Italy

Roberta Masella,

National Institute of Health (ISS), Italy

*Correspondence:

Åslaug O. Matre

aslaug.matre@uib.no

Specialty section This article was submitted to

Nutritional Epidemiology,

a section of the journal

Frontiers in Nutrition

Received: 16 December 2020

Accepted: 11 February 2021

Published: 04 March 2021

Citation:

Matre ÅO, Van Parys A, Olsen T,

Haugsgjerd TR, Baravelli CM,

Nygård O, Dierkes J and Lysne V (2021) The Association of Meat Intake

With All-Cause Mortality and Acute Myocardial Infarction Is

Age-Dependent in Patients With

Stable Angina Pectoris.

Front. Nutr. 8:642612.

doi: 10.3389/fnut.2021.642612

\section{The Association of Meat Intake With All-Cause Mortality and Acute Myocardial Infarction Is Age-Dependent in Patients With Stable Angina Pectoris}

\author{
Åslaug O. Matre ${ }^{1,2 *}$, Anthea Van Parys ${ }^{2}$, Thomas Olsen ${ }^{3}$, Teresa R. Haugsgjerd ${ }^{4}$, \\ Carl M. Baravelli ${ }^{5}$, Ottar Nygård ${ }^{1,2,6}$, Jutta Dierkes ${ }^{2,7}$ and Vegard Lysne ${ }^{1,2,6}$ \\ ${ }^{1}$ Department of Clinical Science, Centre for Nutrition, University of Bergen, Bergen, Norway, ${ }^{2}$ Mohn Nutrition Research \\ Laboratory, Centre for Nutrition, University of Bergen, Bergen, Norway, ${ }^{3}$ Department of Nutrition, Institute of Basic Medical \\ Sciences, University of Oslo, Oslo, Norway, ${ }^{4}$ Department of Global Public Health and Primary Care, University of Bergen, \\ Bergen, Norway, ${ }^{5}$ Department of Laboratory Medicine and Pathology, Haukeland University Hospital, Bergen, Norway, \\ ${ }^{6}$ Department of Heart Disease, Haukeland University Hospital, Bergen, Norway, ${ }^{7}$ Department of Clinical Medicine, University \\ of Bergen, Bergen, Norway
}

Background: Red and processed meat intake have been associated with increased risk of morbidity and mortality, and a restricted intake is encouraged in patients with cardiovascular disease. However, evidence on the association between total meat intake and clinical outcomes in this patient group is lacking.

Objectives: To investigate the association between total meat intake and risk of all-cause mortality, acute myocardial infarction, cancer, and gastrointestinal cancer in patients with stable angina pectoris. We also investigated whether age modified these associations.

Materials and Methods: This prospective cohort study consisted of 1,929 patients (80\% male, mean age 62 years) with stable angina pectoris from the Western Norway B-Vitamin Intervention Trial. Dietary assessment was performed by the administration of a semi-quantitative food frequency questionnaire. Cox proportional hazards models were used to investigate the association between a relative increase in total meat intake and the outcomes of interest.

Results: The association per $50 \mathrm{~g} / 1,000 \mathrm{kcal}$ higher intake of total meat with morbidity and mortality were generally inconclusive but indicated an increased risk of acute myocardial infarction [HR: $1.26(95 \% \mathrm{Cl}: 0.98,1.61)]$ and gastrointestinal cancer [1.23 $(0.70,2.16)]$. However, we observed a clear effect modification by age, where total meat intake was associated with an increased risk of mortality and acute myocardial infarction among younger individuals, but an attenuation, and even reversal of the risk association with increasing age. 


\begin{abstract}
Conclusion: Our findings support the current dietary guidelines emphasizing a restricted meat intake in cardiovascular disease patients but highlights the need for further research on the association between meat intake and health outcomes in elderly populations. Future studies should investigate different types of meat separately in other CVD-cohorts, in different age-groups, as well as in the general population.
\end{abstract}

Keywords: meat, acute myocardial infarction, cancer, mortality, effect modification, gastrointestinal cancer, stable angina pectoris, cardiovascular disease

\section{INTRODUCTION}

Meat consumption has increased considerably worldwide in the last decades (1). Meat is the edible portion of animals and includes muscles, fats, tendons, ligaments, and offal. Meat can be classified as red or white; red meat usually includes meat from cattle, pigs, and sheep, whereas white meat includes meat from poultry (2). As a food group, meat is an important source of several essential nutrients, including protein, thiamin, niacin, vitamin B-6 and B-12, zinc, selenium, and heme iron. Red meat is also a major source of saturated fatty acids, and processed meat products are major contributors to salt intake (3). High consumption of red and processed meat has been associated with increased risk of several adverse health outcomes, including overweight and obesity (4), type 2 diabetes mellitus (5), cardiovascular disease (CVD) (6), cancer (7), and all-cause mortality (8) in initially healthy populations. Particularly, dietary intakes of red and processed meat have gained attention for their association with increased colorectal cancer risk (9). In contrast, less evidence has been accrued with respect to populations with pre-existing disease. Nevertheless, the World Cancer Research Fund recommends restricting the consumption of red and processed meat (10), which has become a cornerstone of dietary guidelines in the Western world (11).

Current dietary guidelines to reduce the risk of CVD also emphasize reduced intake of dietary sources of trans- and saturated fatty acids, including red and processed meat (12). However, data on the association between meat intake and clinical outcomes among CVD patients are lacking. In this study, we aimed to investigate the association between total meat intake and risk of all-cause mortality, and incident acute myocardial infarction (AMI), cancer, and gastrointestinal (GI)cancer in patients with established CVD. Furthermore, because meat intake can contribute to energy and nutrient sufficiency in an aging population prone to malnutrition (13) we also investigated the potential effect modification by age.

\section{SUBJECTS AND METHODS Study Cohort}

The population under study consisted of 1,929 patients ( $80 \%$ male, mean age 62 years) who were participating in

Abbreviations: AMI, Acute myocardial infarction; CHD, Coronary heart disease; CVD, Cardiovascular disease; E\%, Energy \%; FFQ, Food frequency questionnaire; GI, Gastrointestinal; HCA, Heterocyclic amines; ICD, International classifications of diseases; NOC, N-nitroso compound; PAH, Polycyclic aromatic hydrocarbons; WENBIT, Western Norway B-vitamin Intervention Trial. the Western Norway B-vitamin Intervention Trial (WENBIT, NCT00354081). A total of 3,090 patients were included in WENBIT, which was a randomized, double-blind, placebocontrolled trial conducted between 1999 and 2004 investigating the effect of treatment of homocysteine-lowering B-vitamins on mortality and cardiovascular outcomes. Inclusion criteria for participation in the trial were males and females $>18$ years with suspected stable angina pectoris who were undergoing coronary angiography at Haukeland University Hospital (Bergen, Norway) or Stavanger University Hospital (Stavanger, Norway). Exclusion criteria were unavailability for follow-up, participation in other trials, known alcohol abuse, severe mental illness, or cancer. The trial has been described in detail elsewhere $(14,15)$. For the current analyses, we included only patients with confirmed stable angina pectoris $(n=2,573)$. We excluded patients with missing ( $n=485)$ or incomplete ( $>1$ blank page in the FFQ, $n=80$ ) dietary data, and implausible reporters using simple criteria (16) (self-reported energy intake $<717 \mathrm{kcal}$ or $>3,585 \mathrm{kcal}(<3,000$ or $>15,000 \mathrm{~kJ})$ for females, and $<789$ or $>4,183 \mathrm{kcal}(<3,300$ or $>17,500 \mathrm{~kJ}$ ) for males, $n=27)$. We also excluded patients with a very high reported alcohol intake ( $>10 \mathrm{E} \%, n=52)$, leaving a total of 1,929 patients eligible for analyses. A flowchart illustrating the inclusion process is provided in Figure $\mathbf{1}$.

\section{Data Sources}

Data on lifestyle factors and medical history were obtained from self-reported questionnaires and verified by hospital records. Patients were defined as smokers if they reported being current smokers, had quit within the last 4 weeks, or had plasma cotinine levels > $85 \mathrm{nmol} / \mathrm{L}$. Diabetes mellitus was defined according to preexisting diagnosis, plasma $\mathrm{HbA} 1 \mathrm{c}>6.5 \%$, fasting blood glucose $>7 \mathrm{mmol} / \mathrm{L}$ or non-fasting blood glucose $>11.1 \mathrm{mmol} / \mathrm{L}$. Blood samples and routine laboratory analyses were performed at the recruiting hospitals using standard methods.

Dietary data were obtained from a self-administered semiquantitative food frequency questionnaire (FFQ), which was given at the first visit and returned at the 1-month followup visit, or by mail. The FFQ was designed to capture the habitual Norwegian diet and consisted of 169 food items grouped according to Norwegian meal patterns. Patients were asked to answer the questionnaire based on their food habits the year before the study. The data were converted from portion sizes and household measures into grams per day. Nutrient intake was calculated by using "Kostberegningssystemet" version 3.2, developed by the Department of Nutrition, University of Oslo, Norway. 


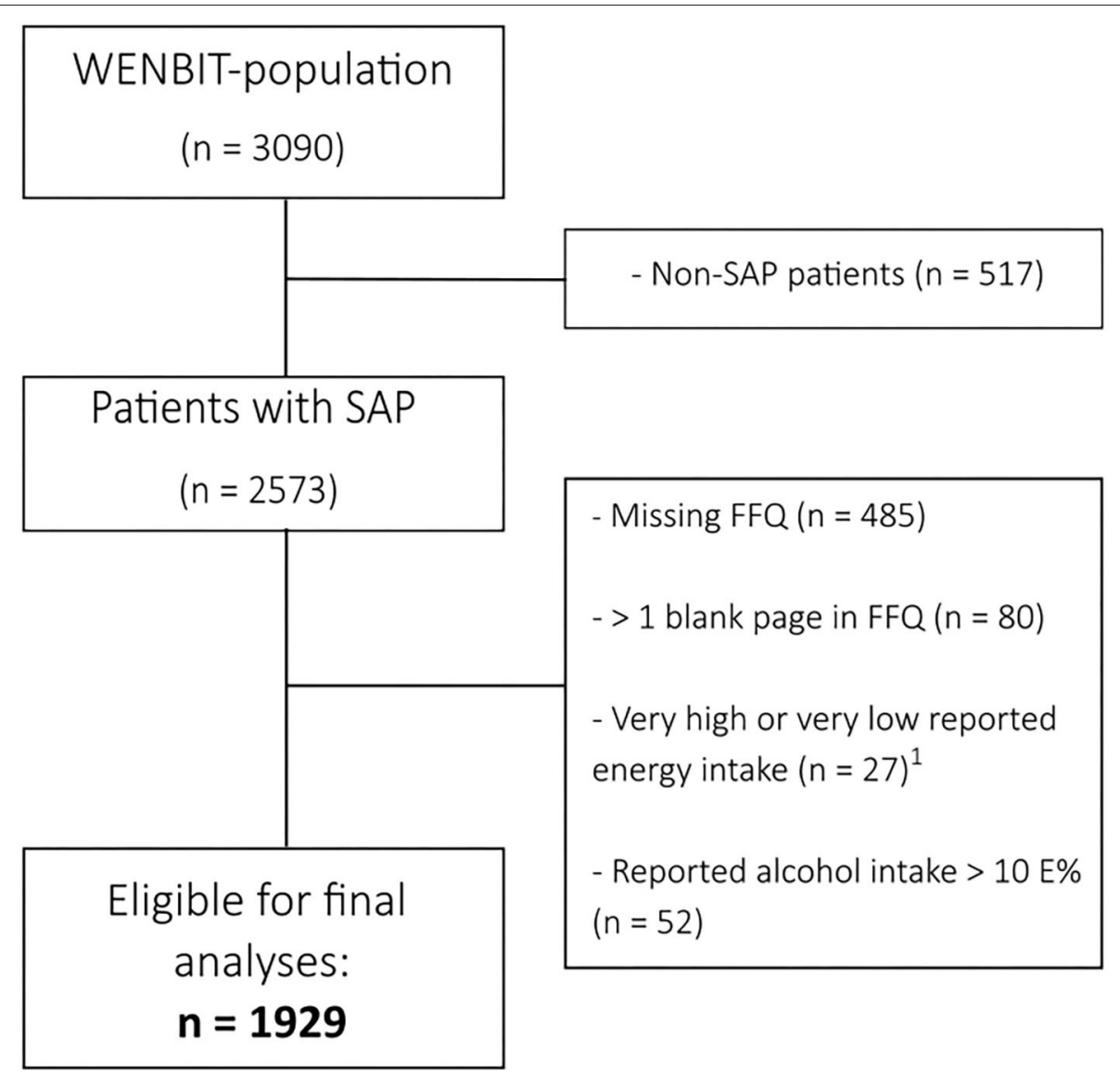

FIGURE 1 | Flowchart illustrating the selection of patients from the WENBIT-cohort. ${ }^{1}$ Self-reported energy intake $<717 \mathrm{kcal}$ or $>3,585 \mathrm{kcal}$ ( $<3,000$ or $>15,000 \mathrm{~kJ}$ ) for females, and $<789$ or $>4,183$ kcal ( $<3,300$ or $>17,500$ kJ) for males. FFQ, Food frequency questionnaire; SAP, Stable angina pectoris; WENBIT, Western Norway B-vitamin Intervention Trial.

\section{Ethical Considerations}

The study was carried out according to the Declaration of Helsinki and was approved by The Regional Committee for Health Research Ethics and The Norwegian Data Inspectorate. All patients provided written informed consent.

\section{Exposure}

Due to the FFQ used for dietary assessment, it was not possible to distinguish between different types of meat. Accordingly, the exposure in this study was total meat intake. For cold cuts, the frequency of consumption was given as times per week, and portion sizes were given as per slice of bread. For meat products used in dishes, the frequency was given as time per month, and portion sizes as slices, pieces, or by volume.

\section{Clinical Endpoints}

All-cause mortality, AMI, cancer, and GI-cancer were chosen as primary outcomes of interest. AMI included both fatal- and non-fatal AMI (International Classification of Diseases (ICD)10 codes: I21, I22, I46.1, R96, R98). Cancer covered malignant neoplasms of all sites (ICD-10 codes: C00-C97), whereas GIcancer included malignant neoplasms in the GI-tract, and accessory organs of digestion, including liver, gallbladder, and pancreas (ICD-10 codes: C15-C26). Information on mortality was obtained from the Cause of Death Registry at the Norwegian Institute of Public Health (17), information on AMI was obtained from the Cardiovascular disease in Norway-project (18), while information on cancer was obtained from the Cancer Registry of Norway (19).

\section{Statistical Analyses}

All statistical analyses were performed using R, version 4.0.2 (The R Foundation for Statistical Computing, Vienna, Austria), and the packages within the Tidyverse (dplyr, tidyr, broom, purrr, stringr, rlang, and ggplot2) (20), skimr, survival, and ggridges. The analytic code is available in the Supplementary Material. To adjust for self-reported energy intake, the nutrient density method was used (21), expressing foods as g/1,000 kcal and macronutrients as energy \% (E\%). Cox proportional hazard regression models, with days since baseline as time scale, were used to investigate the association between meat intake and the outcomes of interest, and the HRs are reported per 50 $\mathrm{g} / 1,000 \mathrm{kcal}$ increment in daily meat intake. The proportional hazard assumption was tested using the cox.zph() function in 
the survival package, and by visually inspecting Schoenfeld residuals. Confounding variables were identified a priori, based on subject matter knowledge at the time of writing and previous literature, using a directed acyclic graph approach (Figure 2). To estimate the relative effect of increasing meat intake, selfreported total energy intake was included as a covariate in all models. The HR is then interpreted as the change in the estimated risk for each $50 \mathrm{~g} / 1,000 \mathrm{kcal}$ increment in meat intake, with a concomitant isoenergetic decrease in intake of other foods (22). The main model (Model 1) included age, sex, and smoking as covariates. Model 2 was additionally adjusted for BMI. Model 3 and 4 were adjusted for the same covariates as Model 1 and 2 , respectively, except age and BMI being included as penalized splines (using the pspline function in the survival package). The same models were applied to all outcomes. The analyses were also conducted for males and females separately and presented in Supplementary Table 3.

To explore potential non-linear relationships, meat intake was modeled as a penalized spline in a model adjusted for Model 1 (Figure 3) and Model 2 (Supplementary Figure 1) covariates, and the partial hazard (95\% CI) of increasing meat intake was visualized. We further explored whether age modified the association for meat intake with the endpoints, by including an interaction term to Model 1 (Figure 4) and Model 2 (Supplementary Figure 2). The conditional HRs (95\% CI) per $50 \mathrm{~g} / 1,000 \mathrm{kcal}$ higher intake of meat was then plotted across age to visualize the potential effect modification. Models with and without interaction terms were compared by likelihood ratio tests and presented in Supplementary Table 4.

In line with the most recent statement from the American Statistical Association on $p$-values (23), we decided not to dichotomize the results based on $p$-value cutoffs. We rather describe our data emphasizing effect sizes, the variation, and uncertainty of the data as expressed by CIs (24). The importance and practical implications of the observations were evaluated using subject matter knowledge and prior evidence.

\section{RESULTS}

\section{Patient Characteristics}

Key characteristics of the 1,929 patients and the associations with meat intake are presented in Table 1, with a more complete description of the study population provided in Supplementary Table 1. In the final cohort of 1,929 patients, 1,539 patients $(79.8 \%)$ were male, and the mean \pm SD age was $62 \pm 10$ years. A total of 836 patients (43.3\%) had experienced an AMI previously. Patients with a relatively higher meat intake were more likely to be younger, male, smokers, diabetic, and to have a higher BMI and larger waist circumference.

\section{Dietary Intake}

The daily dietary intake of the macronutrients (given in E\%) and food groups (given in $\mathrm{g} / 1,000 \mathrm{kcal}$ ), and their associations with meat intake are provided in Table 2. A more complete description of the dietary intake is provided in Supplementary Table 2 . The mean daily reported meat intake was $54.9 \pm 22.9 \mathrm{~g} / 1,000 \mathrm{kcal}$ (absolute intakes: $123 \pm 62 \mathrm{~g}$ and $86 \pm 46 \mathrm{~g}$ for males and females, respectively). Relatively higher meat intake was associated with slightly lower consumptions of dairy products, fruits and berries, and bread. As expected, given the nutrient content of meat, relatively higher meat intake was positively associated with intake of fats (both saturated-, monounsaturated-, and polyunsaturated fats), protein, and cholesterol, and inversely associated with carbohydrate intake.

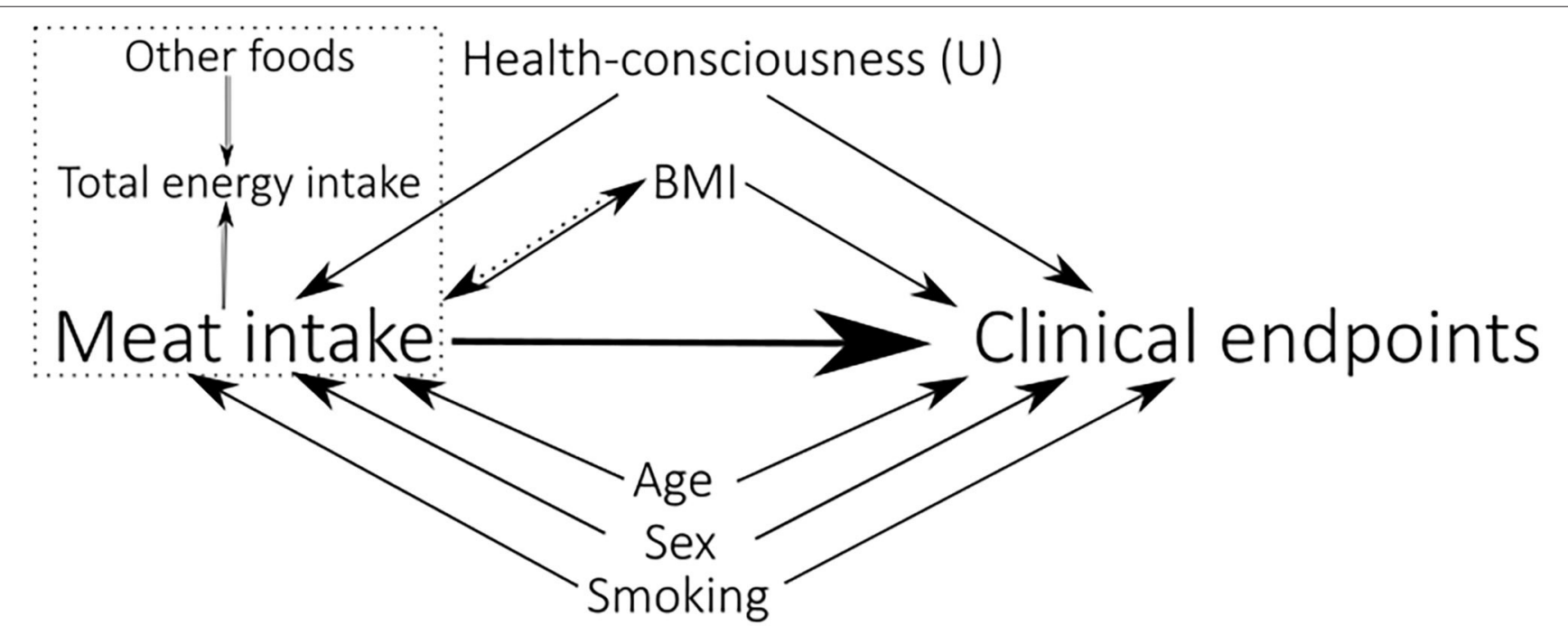

FIGURE 2 | A directed acyclic graph illustrating the model building process, representing the causal assumptions that were made. The variables pointing toward both Meat intake and Clinical endpoints (all-cause mortality, AMI, cancer, and Gl-cancer), are considered confounders for these associations. The (U) indicates that the variable is unmeasured. BMI is modeled both as a mediator (Model 1) and a confounder (Model 2). A dashed rectangle encompasses variables occurring at the same time. 


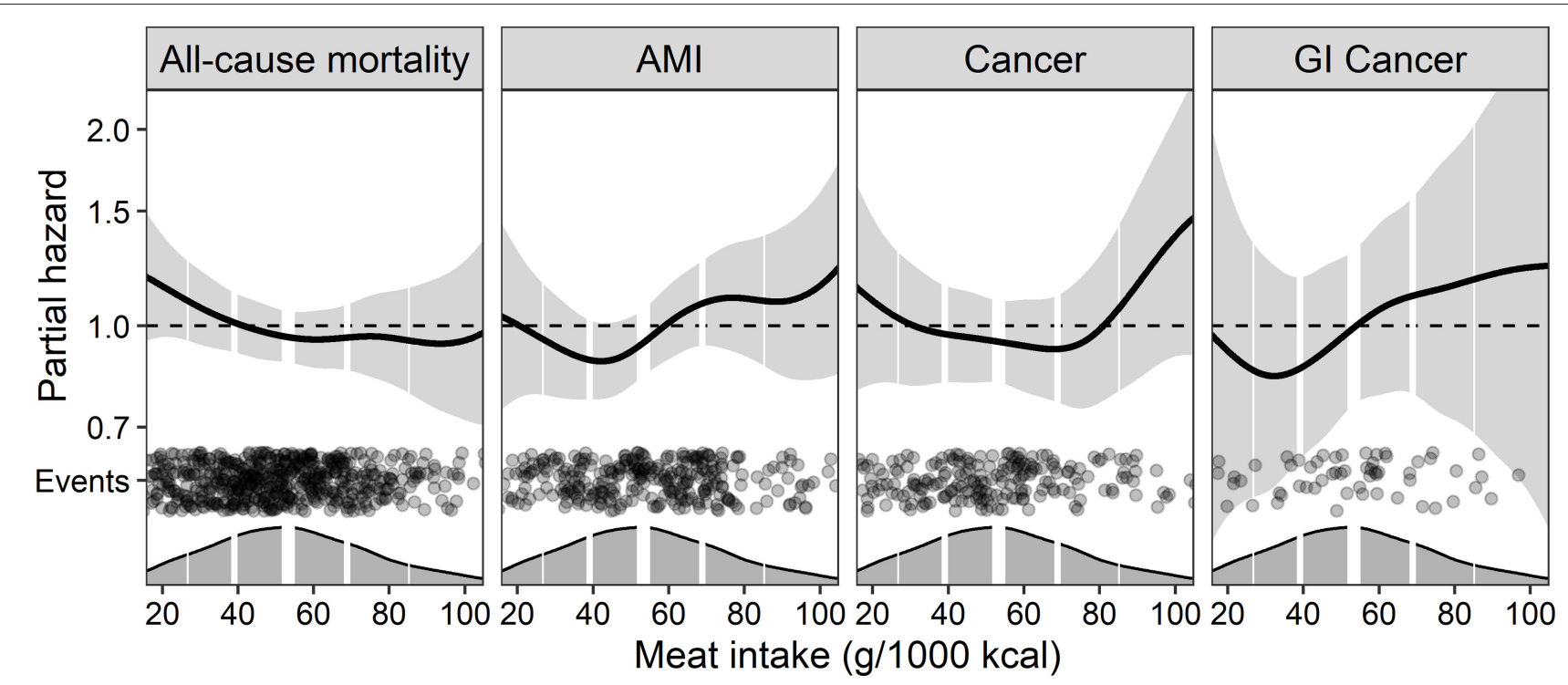

FIGURE 3 | The continuous association between energy-adjusted total meat intake and the risk of clinical outcomes using generalized additive models. The models were adjusted for Model 1 covariates (self-reported energy intake, age, sex, and smoking). Light gray areas around the central line represent 95\% Cls of the hazard estimates. Dark gray areas at the $\mathrm{x}$-axis are density plots of meat intake (g/1,000 kcal), and the vertical white lines indicate the 10th, 25th, 50th (bold line), 75th, and 90th percentiles. The black dots indicate events at the different intake levels of meat. The plots are cropped at the 2.5th and 97.5th percentiles of reported meat intake. AMl, Acute myocardial infarction; Gl, Gastrointestinal.

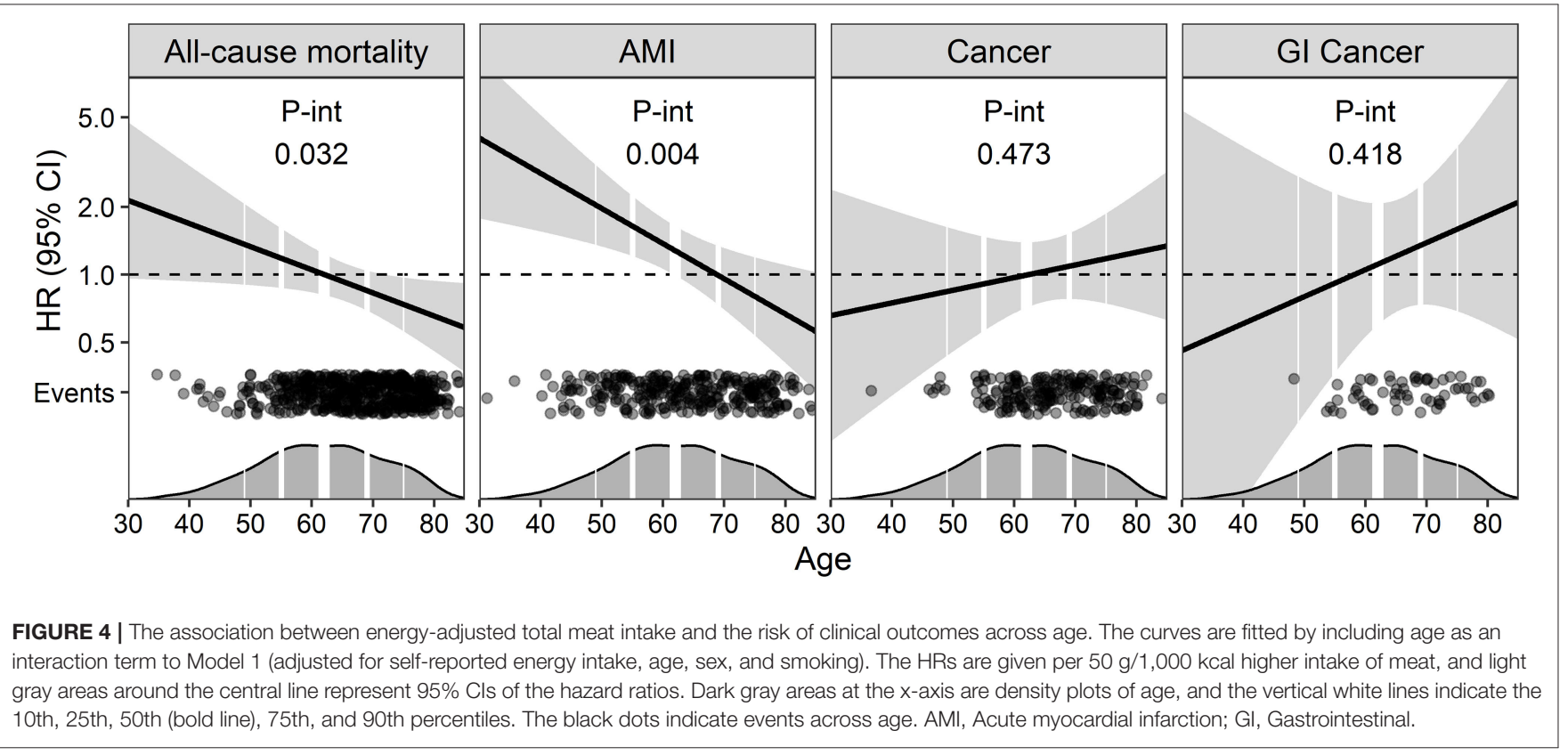

\section{Meat Intake and Risk of Clinical Endpoints All-Cause Mortality}

A total of $572(29.8 \%)$ patients died after a median followup of 14.1 (25th, 75th percentiles: 12.8, 15.5) years. In Model 1, we observed a 9\% reduced risk of all-cause mortality [HR: 0.91 (95\% CI: $0.75,1.10)$ ] per $50 \mathrm{~g} / 1,000$ kcal higher intake of meat, but the data was compatible with both $25 \%$ reduced risk and $10 \%$ increased risk. Further adjustments did not have any pronounced impact on the result (Table 3), but the association appeared stronger in females (Supplementary Table 3). The association between meat intake and all-cause mortality was age-dependent, with an increased risk observed at younger ages, but an attenuation and even reversal of the risk association observed with increasing age (Figure 4). Including age as an interaction term improved model fit (Supplementary Table 4). 
TABLE 1 | Key characteristics of the patients included in the study $(n=1,929)$.

\begin{tabular}{|c|c|c|c|c|c|c|c|}
\hline \multirow[t]{2}{*}{ Variable } & \multirow[t]{2}{*}{ Total cohort ${ }^{\mathrm{a}}$} & \multicolumn{5}{|c|}{ Percentiles } & \multirow[t]{2}{*}{ Association with meat intake ${ }^{b}$} \\
\hline & & 10 & 25 & 50 & 75 & 90 & \\
\hline Age, years & $61.8 \pm 9.7$ & 49.0 & 55.0 & 62.0 & 69.0 & 75.0 & $r=-0.20(-0.24,-0.16)$ \\
\hline BMl, kg/m² & $26.4 \pm 3.7$ & 22.0 & 24.0 & 26.0 & 28.0 & 31.0 & $r=0.14(0.10,0.18)$ \\
\hline Waist circumference, cm & $96.4 \pm 11.1$ & 83.0 & 90.0 & 96.0 & 103 & 110 & $r=0.12(0.08,0.17)$ \\
\hline Male sex & $1,539(79.8 \%)$ & - & - & - & - & - & $d=3.6(1.1,6.1)$ \\
\hline Hypertension & $911(47.2 \%)$ & - & - & - & - & - & $d=-0.4(-2.5,1.6)$ \\
\hline Diabetes $^{c}$ & $590(30.6 \%)$ & - & - & - & - & - & $d=3.5(1.3,5.7)$ \\
\hline Smoker ${ }^{d}$ & 560 (29.0\%) & - & - & - & - & - & $d=6.4(4.2,8.7)$ \\
\hline
\end{tabular}

a Presented as mean $\pm S D$ or $n(\%)$.

${ }^{b}$ Given as $d=$ mean difference $(95 \% \mathrm{Cl})$, or $r=$ Pearson's correlation coefficient (95\% Cl), calculated on log transformed data.

${ }^{c}$ Preexisting diagnose of diabetes, or with fasting blood glucose $>7 \mathrm{mmol} / \mathrm{L}$, non-fasting blood-glucose $>11.1 \mathrm{mmol} / \mathrm{L}$, or $\mathrm{HbA} 1 \mathrm{C}>6.5 \%$.

${ }^{d}$ Self-reported current smokers, or having quit within the last 4 weeks, or with plasma cotinine levels $\geq 85 \mathrm{nmol} / \mathrm{L}$.

TABLE 2 | The daily dietary intake of the patients $(n=1,929)$.

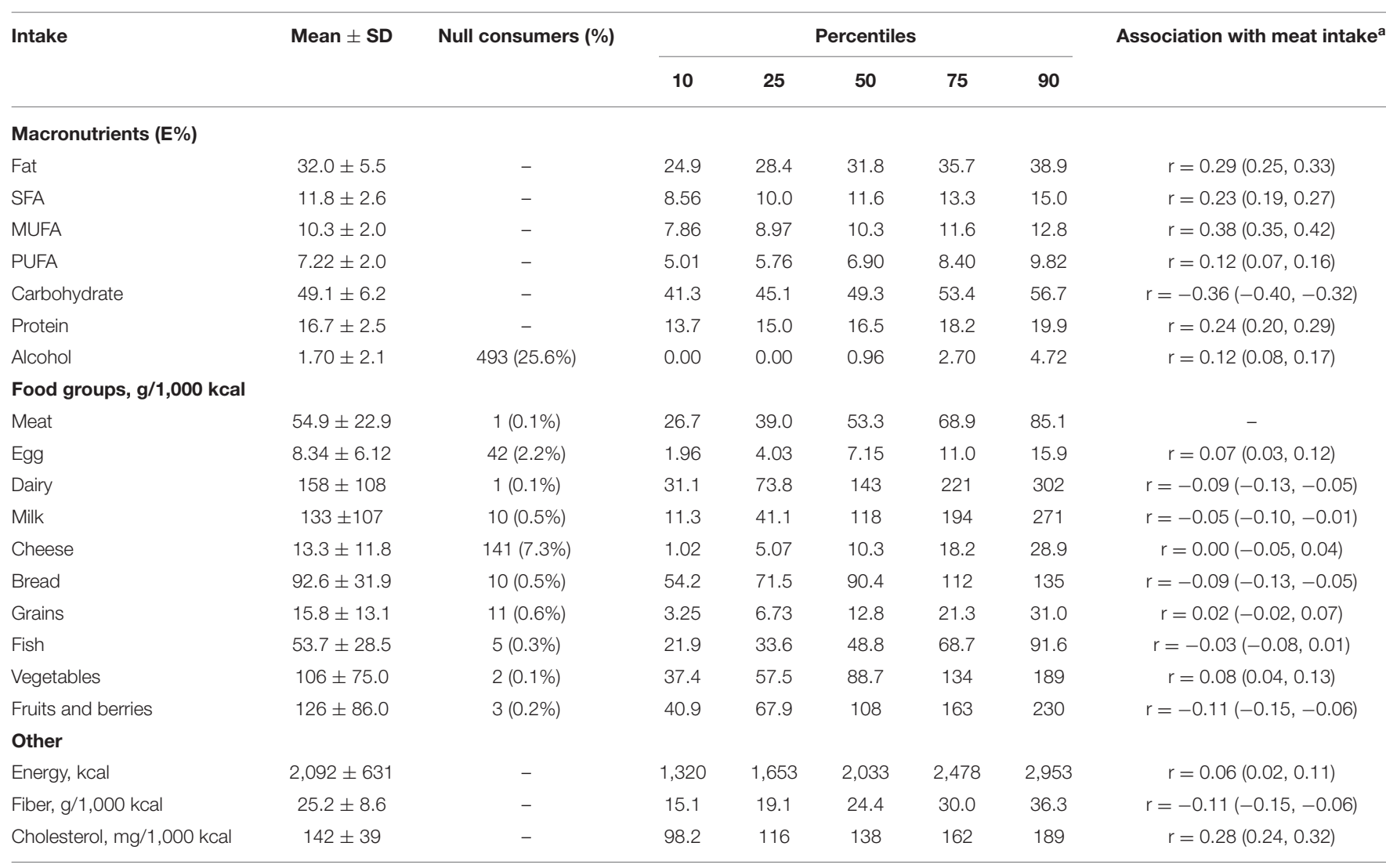

${ }^{a}$ Given as $r=$ Pearson's correlation coefficient $(95 \% \mathrm{Cl})$, calculated on log-transformed data.

MUFA, Monounsaturated fatty acid; PUFA, Polyunsaturated fatty acid; SFA, Saturated fatty acid.

\section{Acute Myocardial Infarction}

During the follow-up of 7.8 (25th, 75th percentiles: 6.4, 9.1) years, $309(16.0 \%)$ incident cases of AMI were reported. In Model 1, meat intake was associated with a $26 \%$ increased risk of AMI $[1.26(0.98,1.61)]$, per $50 \mathrm{~g} / 1,000 \mathrm{kcal}$ higher intake of meat (Table 3 ). The relationship between meat intake and AMI appeared non-linear, with the increased risk mainly observed in the higher intake ranges of meat (Figure 3 ). The increased risk of AMI appeared to be present at younger ages, but an attenuation of the risk association with increasing age (Figure 4). Including age as an interaction term improved model fit (Supplementary Table 4). 
TABLE 3 | The association between energy-adjusted total meat intake and clinical endpoints - results from the Cox proportional hazard regression model ${ }^{\mathrm{a}}$

\begin{tabular}{|c|c|c|c|c|c|c|c|c|}
\hline & \multicolumn{2}{|c|}{ All-cause mortality } & \multicolumn{2}{|l|}{ AMI } & \multicolumn{2}{|c|}{ Cancer } & \multicolumn{2}{|c|}{ GI-cancer } \\
\hline Number of events (\%) & \multicolumn{2}{|c|}{$574(29.8 \%)$} & \multicolumn{2}{|c|}{309 (16.0\%) } & \multicolumn{2}{|c|}{$213(11.0 \%)$} & \multicolumn{2}{|c|}{$61(3.2 \%)$} \\
\hline $\begin{array}{l}\text { Median follow-up, years } \\
\text { (25th, 75th percentile) }\end{array}$ & \multicolumn{2}{|c|}{$14.1(12.8,15.5)$} & \multicolumn{2}{|c|}{$7.8(6.4,9.1)$} & \multicolumn{2}{|c|}{$8.0(6.6,9.3)$} & \multicolumn{2}{|c|}{$8.1(6.7,9.4)$} \\
\hline Models $^{b}$ & HR (95\% Cl) & $P$-value & HR (95\% Cl) & $P$-value & HR (95\% Cl) & $P$-value & HR (95\% Cl) & $P$-value \\
\hline Model 1 & $0.91(0.75,1.10)$ & 0.333 & $1.26(0.98,1.61)$ & 0.077 & $1.04(0.76,1.42)$ & 0.806 & $1.23(0.70,2.16)$ & 0.478 \\
\hline Model 2 & $0.88(0.72,1.07)$ & 0.189 & $1.21(0.93,1.56)$ & 0.150 & $1.03(0.76,1.42)$ & 0.832 & $1.16(0.65,2.06)$ & 0.613 \\
\hline Model 3 & $0.89(0.73,1.08)$ & 0.247 & $1.23(0.95,1.59)$ & 0.109 & $1.05(0.77,1.43)$ & 0.750 & $1.25(0.71,2.19)$ & 0.444 \\
\hline Model 4 & $0.88(0.72,1.07)$ & 0.202 & $1.20(0.93,1.56)$ & 0.164 & $1.05(0.77,1.43)$ & 0.772 & $1.17(0.66,2.08)$ & 0.594 \\
\hline
\end{tabular}

${ }^{a}$ HRs (95\% Cl) are given per daily $50 \mathrm{~g} / 1,000 \mathrm{kcal}$ higher intake of meat. ${ }^{b}$ Model 1: Adjusted for age, sex, smoking, and total energy intake. Model 2: Adjusted for age, sex, smoking,

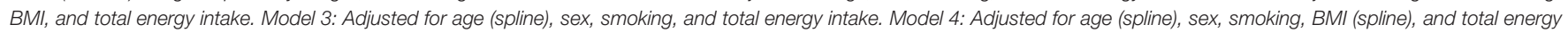
intake. AMI, Acute myocardial infarction; Gl, Gastrointestinal.

\section{Cancer}

In total, $213(11.0 \%)$ patients were diagnosed with cancer during the follow-up of 8.0 (25th, 75th percentiles: $6.6,9.3)$ years. In Model 1, meat intake was associated with a $4 \%$ increased risk of cancer per $50 \mathrm{~g} / 1,000 \mathrm{kcal}$ higher intake of meat per day. However, the low precision rendered the data inconclusive [1.04 $(0.76,1.42)]$. Further adjustments did not appreciably affect the results (Table 3). Continuous analyses indicated a non-linear association with cancer, with an increased risk of cancer at higher intake-levels of meat, but not at intakes in the low- to moderate range (Figure 3 ).

A total of 61 (3.2\%) patients were diagnosed with GI-cancer during follow-up of 8.1 (25th, 75th percentiles: $6.7,9.4$ ) years. In Model 1, we observed a $23 \%$ increased risk of GI-cancer per 50 $\mathrm{g} / 1,000 \mathrm{kcal}$ higher intake of meat $[1.23(0.70,2.16)]$, but the data was compatible both with $30 \%$ reduced risk and $116 \%$ increased risk of GI-cancer. Including BMI as a covariate in Model 2 and Model 4 slightly attenuated the association (Table 3 ). The association with GI-cancer appeared slightly J-shaped (Figure 3).

\section{DISCUSSION}

\section{Main Findings}

In this study, the association of a higher meat intake with morbidity and mortality were generally inconclusive but indicated an increased risk of AMI and GI-cancer. However, we observed a clear effect modification by age, where total meat intake was associated with an increased risk of mortality and AMI at younger ages, but an attenuation and even reversal of the risk association observed with increasing age.

\section{Discussion of the Findings}

Our findings on AMI and GI-cancer are supported by previously reported findings on red and processed meat in the existing literature based on initially healthy populations $(9,25)$, and provide support to the current dietary guidelines emphasizing a restricted meat consumption in the Western world, in particular at younger ages. However, the reduced risk we observed for all-cause mortality contradicts previously reported findings (8). This unexpected association may partly be explained by the observation of a strong inverse association between meat intake and age in this study population, with the oldest participants having the lowest meat intake. Furthermore, we observed that the association between meat intake and mortality and acute myocardial infarction was different across age, with increased risk in the younger end of the population, but reduced risk at higher ages. Older populations typically have a lower dietary intake and a higher prevalence of undernutrition compared to younger populations (26), which is associated with an increased risk of mortality (27). In addition to contributing to energy intake, meat can be an important source of essential micronutrients and protein of high biological value. Increased protein intake has previously been associated with improved health in older populations (28). Thus, we may speculate that a higher meat intake may be more beneficial, or less harmful, in elderly populations compared to younger populations. Key et al. (25) reported an association between red and processed meat, and increased risk of myocardial infarction in participants $<65$ years from the EPIC (European Prospective Investigation into Cancer and Nutrition) cohort. However, the results indicated a reduced risk among the participants $\geq 65$ years, supporting the current findings on AMI. Furthermore, Levine et al. (29) reported an association between moderate to high protein intakes, and increased risk of all-cause mortality among participants aged 50-65 years in a United States population. When they controlled for the E\% from animal protein, this association diminished, suggesting that the observed association was driven by high intakes of animal protein. However, among participants aged $\geq 66$ years, they observed that higher protein intake was associated with reduced risk of all-cause mortality, without controlling for animal protein, which is similar to the current observations with meat intake. Conversely, Letois et al. (30) reported an increased risk of mortality associated with increasing meat intake in a French population aged $\geq 65$ years. Further research on the association between meat intake and health outcomes in elderly populations is needed.

\section{Suggested Underlying Mechanisms}

Several underlying mechanisms have been suggested to explain the observed association between higher meat 
intake and increased risk of cancer and coronary heart disease (CHD) in the existing literature. For cancer, the exact mechanisms are not known but might be attributable to the formation of the mutagenic compounds polycyclic aromatic hydrocarbons (PAHs), heterocyclic amines (HCAs), and $\mathrm{N}$-nitroso compounds (NOCs). PAHs and HCAs are formed during cooking of meat at high temperatures (31), and NOCs may be found in foods processed by smoking or in processed meat containing nitrite. Both PAHs, HCAs, and NOCs have been mechanistically linked to colorectal cancer (32).

It has been suggested that the content of fats in meat may be an explanation for the observed risk of $\mathrm{CHD}$, but the total evidence suggests that other components of meat that are most relevant for cardiometabolic effects (33). The high content of salt in processed meat is suggested to account for a substantial proportion of the observed risk of $\mathrm{CHD}$, due to the effects of sodium on blood pressure, and the observed relationship between blood pressure and clinical events of CHD (33). It has also been suggested that the mechanisms linking red and processed meat to the observed risk of CHD are the same as the suggested mechanisms linking red and processed meat to the observed risk of type 2 diabetes mellitus (34). However, the exact mechanisms for $\mathrm{CHD}$ are not clear and should be further investigated.

\section{Strengths and Limitations}

The large sample size and long follow-up are some of the main strengths of the current study. The study population consisted of patients in Western-Norway with established coronary artery disease, and it has previously been reported that the participants in WENBIT are comparable to samples of patients with verified coronary artery disease in Europe (14). However, generalizability toward the general population is limited. To identify confounders, we used Directed acyclic graphs, which is a widely used tool for causal inference. Nevertheless, the current study was an observational study, and, therefore, residual confounding cannot be excluded. Also, dietary intake is associated with several social and behavioral confounders, such as health-consciousness, physical activity, and socioeconomic status that we did not measure. Furthermore, all patients received standard dietary advice for patients with cardiovascular disease when they were included in the study. Most patients conducted the FFQ after they had received these dietary advices, which may have affected how they responded to the questionnaire. As a dietary assessment was conducted only on the first visit, we do not know whether the patients changed their diet during follow-up. Dietary data derived from FFQs are also known to be affected by substantial measurement error, and measurement error in meat intake may lead to regression dilution bias and loss of statistical power to detect a relationship (35). However, we adjusted for self-reported energy intake using the nutrient density method, and by including self-reported total energy intake as a covariate in the multivariate models, which helps to attenuate the measurement error and improves precision when estimating diet-disease relationships $(21,36)$. The present FFQ did not allow for distinguishment between different types of meat. However, a comparison with the national dietary survey from 1997, "Norkost 2" (37) shows that the meat intake in this study population was at the same level as the general population in Norway. Food balance sheets from Norway (38) show that red meat dominated the meat intake in 1999 , while white meat was only a small proportion.

In conclusion, in patients with stable angina pectoris, the association of a higher total meat intake with mortality and morbidity were in general inconclusive but indicated an increased risk of AMI and gastrointestinal cancer, particularly at higher meat intakes. The associations with all-cause mortality and AMI differed across ages, with increased risk observed at younger ages, but an attenuation, and even reversal of the risk association with increasing age. The findings from this study support the current dietary guidelines emphasizing a restricted meat intake in patients with CVD but highlight the need for more research on the association between meat intake and health outcomes in elderly populations. Future studies should investigate different types of meat separately in other CVD-cohorts, in different age-groups, as well as in the general population.

\section{DATA AVAILABILITY STATEMENT}

The raw data supporting the conclusions of this article will be made available by the authors, without undue reservation.

\section{ETHICS STATEMENT}

The studies involving human participants were reviewed and approved by the Regional Committee for Health Research Ethics and the Norwegian Data Inspectorate. The patients/participants provided their written informed consent to participate in this study.

\section{AUTHOR CONTRIBUTIONS}

$\AA \mathrm{M}$ and VL analyzed data. ÅM had primary responsibility for final content and wrote the paper. $\mathrm{AV}, \mathrm{TO}, \mathrm{TH}, \mathrm{CB}$, $\mathrm{ON}$, JD, and VL reviewed and edited the manuscript. All authors have read and approved the final version of the manuscript.

\section{SUPPLEMENTARY MATERIAL}

The Supplementary Material for this article can be found online at: https://www.frontiersin.org/articles/10.3389/fnut.2021. 642612/full\#supplementary-material 


\section{REFERENCES}

1. Godfray HCJ, Aveyard P, Garnett T, Hall JW, Key TJ, Lorimer J, et al. Meat consumption, health, and the environment. Science. (2018) 361:eaam5324. doi: 10.1126/science.aam5324

2. Keeton JT, Dikeman ME. 'Red' and 'white' meats-terms that lead to confusion. Anim Front. (2017) 7:29-33. doi: 10.2527/af.201 7.0440

3. Pereira PM, Vicente AF. Meat nutritional composition and nutritive role in the human diet. Meat Sci. (2013) 93:58692. doi: 10.1016/j.meatsci.2012.09.018

4. Fogelholm M, Anderssen S, Gunnarsdottir I, Lahti-Koski M. Dietary macronutrients and food consumption as determinants of long-term weight change in adult populations: a systematic literature review. Food Nutr Res. (2012) 56. doi: 10.3402/fnr.v56i0.19103

5. Neuenschwander M, Ballon A, Weber KS, Norat T, Aune D, Schwingshackl $\mathrm{L}$, et al. Role of diet in type 2 diabetes incidence: umbrella review of meta-analyses of prospective observational studies. BMJ. (2019) 366:12368. doi: 10.1136/bmj.12368

6. Bechthold A, Boeing H, Schwedhelm C, Hoffmann G, Knüppel S, Iqbal K, et al. Food groups and risk of coronary heart disease, stroke and heart failure: a systematic review and dose-response meta-analysis of prospective studies. Crit Rev Food Sci Nutr. (2019) 59:1071-90. doi: 10.1080/10408398.2017. 1392288

7. World Cancer Research Fund/American Institute for Cancer Research. Continous Update Project Expert Report 2018. Meat, Fish and Dairy Products and the Risk of Cancer. Available online at: dietandcancerreport.org

8. Schwingshackl L, Schwedhelm C, Hoffmann G, Lampousi AM, Knüppel S, Iqbal K, et al. Food groups and risk of all-cause mortality: a systematic review and meta-analysis of prospective studies. Am J Clin Nutr. (2017) 105:1462-73. doi: 10.3945/ajcn.117.153148

9. Chan DSM, Lau R, Aune D, Vieira R, Greenwood DC, Kampman E, et al. Red and processed meat and colorectal cancer incidence: meta-analysis of prospective studies. PLoS ONE. (2011) 6:e20456. doi: 10.1371/journal.pone.0020456

10. World Cancer Research Fund/American Institute for Cancer Research. Continous Update Project Expert Report 2018. Recommendations and Public Health and Policy Implications. Available online at: dietandcancerreport.org

11. Herforth A, Arimond M, Álvarez-Sánchez C, Coates J, Christianson K, Muehlhoff E. A global review of food-based dietary guidelines. Adv Nutr. (2019) 10:590-605. doi: 10.1093/advances/ nmy130

12. Piepoli MF, Hoes AW, Agewall S, Albus C, Brotons C, Catapano AL, et al. 2016 European guidelines on cardiovascular disease prevention in clinical practice: the Sixth Joint Task Force of the European Society of Cardiology and Other Societies on Cardiovascular Disease Prevention in Clinical Practice (constituted by representatives of 10 societies and by invited experts) Developed with the special contribution of the European Association for Cardiovascular Prevention \&amp; Rehabilitation (EACPR). Eur Heart J. (2016) 37:2315-81. doi: 10.1093/eurheartj/ehw106

13. de Morais C, Oliveira B, Afonso C, Lumbers M, Raats M, de Almeida MD. Nutritional risk of European elderly. Eur J Clin Nutr. (2013) 67:12159. doi: 10.1038/ejcn.2013.175

14. Ebbing M, Bleie $\varnothing$, Ueland PM, Nordrehaug JE, Nilsen DW, Vollset SE, et al. Mortality and cardiovascular events in patients treated with homocysteine-lowering B vitamins after coronary angiography: a randomized controlled trial. JAMA. (2008) 300:795-804. doi: 10.1001/jama.300. 7.795

15. Svingen GFT, Ueland PM, Pedersen EKR, Schartum-Hansen H, Seifert $\mathrm{R}$, Ebbing $\mathrm{M}$, et al. Plasma dimethylglycine and risk of incident acute myocardial infarction in patients with stable angina pectoris. Arterioscler Thromb Vasc Biol. (2013) 33:2041-8. doi: 10.1161/ATVBAHA.113. 301714

16. Rhee JJ, Sampson L, Cho E, Hughes MD, Hu FB, Willett WC. Comparison of methods to account for implausible reporting of energy intake in epidemiologic studies. Am J Epidemiol. (2015) 181:225-33. doi: 10.1093/aje/kwu308
17. Pedersen AG, Ellingsen CL. Data quality in the causes of death registry. Tidsskr Nor Laegeforen. (2015) 135:768-70. doi: 10.4045/tidsskr. 14.1065

18. Sulo G, Igland J, Vollset SE, Nygård O, Øyen N, Tell GS. Cardiovascular disease and diabetes mellitus in Norway during 1994-2009 CVDNOR - a nationwide research project. Norsk Epidemiologi. (2013) 23:1017. doi: 10.5324/nje.v23i1.1609

19. Larsen IK, Småstuen M, Johannesen TB, Langmark F, Parkin DM, Bray F, et al. Data quality at the Cancer Registry of Norway: an overview of comparability, completeness, validity and timeliness. Eur J Cancer. (2009) 45:1218-31. doi: 10.1016/j.ejca.2008.10.037

20. Wickham H, Averick M, Bryan J, Chang W, McGowan LD, François $\mathrm{R}$, et al. Welcome to the Tidyverse. J Open Source Softw. (2019) 4:1686. doi: $10.21105 /$ joss.01686

21. Willett WC, Howe GR, Kushi LH. Adjustment for total energy intake in epidemiologic studies. Am J Clin Nutr. (1997) 65(4 Suppl):1220S-8S; discussion: 9S-31S. doi: 10.1093/ajcn/65.4 $.1220 \mathrm{~S}$

22. Arnold KF, Berrie L, Tennant PWG, Gilthorpe MS. A causal inference perspective on the analysis of compositional data. Int J Epidemiol. (2020) 49:1307-13. doi: 10.1136/jech-2019-SSMabstr acts. 81

23. Wasserstein RL, Lazar NA. The ASA Statement on p-values: context, process, and purpose. Am Statistician. (2016) 70:12933. doi: 10.1080/00031305.2016.1154108

24. Rafi Z, Greenland S. Semantic and cognitive tools to aid statistical science: replace confidence and significance by compatibility and surprise. BMC Med Res Methodol. (2020) 20:244. doi: 10.1186/s12874-02001105-9

25. Key TJ, Appleby PN, Bradbury KE, Sweeting M, Wood A, Johansson I, et al. Consumption of meat, fish, dairy products, and eggs and risk of ischemic heart disease. Circulation. (2019) 139:2835-45. doi: 10.1161/CIRCULATIONAHA.118. 038813

26. Fávaro-Moreira NC, Krausch-Hofmann S, Matthys C, Vereecken C, Vanhauwaert E, Declercq A, et al. Risk factors for malnutrition in older adults: a systematic review of the literature based on longitudinal data. Adv Nutr. (2016) 7:507-22. doi: 10.3945/an.115. 011254

27. Söderström L, Rosenblad A, Adolfsson ET, Saletti A, Bergkvist L. Nutritional status predicts preterm death in older people: a prospective cohort study. Clin Nutr. (2014) 33:354-9. doi: 10.1016/j.clnu.2013. 06.004

28. Wolfe RR. The role of dietary protein in optimizing muscle mass, function and health outcomes in older individuals. $\mathrm{Br}$ $J \quad$ Nutr. (2012) 108(S2):S88-93. doi: 10.1017/S00071145120 02590

29. Levine Morgan E, Suarez Jorge A, Brandhorst S, Balasubramanian P, Cheng C-W, Madia F, et al. Low protein intake is associated with a major reduction in IGF-1, cancer, and overall mortality in the 65 and younger but not older population. Cell Metabolism. (2014) 19:40717. doi: 10.1016/j.cmet.2014.02.006

30. Letois F, Mura T, Scali J, Gutierrez LA, Féart C, Berr C. Nutrition and mortality in the elderly over 10 years of follow-up: the ThreeCity study. Br J Nutr. (2016) 116:882-9. doi: 10.1017/S00071145160 0266X

31. Ali A, Waly M, Devarajan S. Impact of processing meat on the formation of heterocyclic amines and risk of cancer. In: Saad B, Tofalo R, editors. Biogenic Amines in Food: Analysis, Occurrence and Toxicity. 1st ed. The Royal Society of Chemistry (2019). p. 187-211.

32. Cross AJ, Sinha R. Meat-related mutagens/carcinogens in the etiology of colorectal cancer. Environ Mol Mutagen. (2004) 44:44-55. doi: 10.1002/em.20030

33. Micha R, Michas G, Mozaffarian D. Unprocessed red and processed meats and risk of coronary artery disease and type 2 diabetes-an updated review of the evidence. Curr Atheroscler Rep. (2012) 14:51524. doi: $10.1007 / \mathrm{s} 11883-012-0282-8$ 
34. Wolk A. Potential health hazards of eating red meat. J Internal Med. (2017) 281:106-22. doi: 10.1111/joim.12543

35. Freedman LS, Schatzkin A, Midthune D, Kipnis V. Dealing with dietary measurement error in nutritional cohort studies. J Natl Cancer Inst. (2011) 103:1086-92. doi: 10.1093/jnci/djr189

36. Subar AF, Freedman LS, Tooze JA, Kirkpatrick SI, Boushey C, Neuhouser $\mathrm{ML}$, et al. Addressing current criticism regarding the value of selfreport dietary data. J Nutr. (2015) 145:2639-45. doi: 10.3945/jn.115.2 19634

37. Johansson L, Solvoll K. Norkost 1997 - Nationally Representative Dietary Survey in Men and Women Aged 16-79 Years (Norkost 1997 Landsomfattende kostholdsundersøkelse blant menn og kvinner $i$ alderen 16-79 år). Oslo: National Council for Nutrition and Physical Activity (1999).
38. Svennerud M, Bøe E, Romsaas IM. Trends in the Norwegian Diet 2019. Oslo: Norwegian Directorate of Health (2020). p. 102.

Conflict of Interest: The authors declare that the research was conducted in the absence of any commercial or financial relationships that could be construed as a potential conflict of interest.

Copyright (C) 2021 Matre, Van Parys, Olsen, Haugsgjerd, Baravelli, Nygård, Dierkes and Lysne. This is an open-access article distributed under the terms of the Creative Commons Attribution License (CC BY). The use, distribution or reproduction in other forums is permitted, provided the original author(s) and the copyright owner(s) are credited and that the original publication in this journal is cited, in accordance with accepted academic practice. No use, distribution or reproduction is permitted which does not comply with these terms. 